Article

\title{
Targeted Metabolite Profiling-Based Identification of Antifungal 5- $n$-Alkylresorcinols Occurring in Different Cereals against Fusarium oxysporum
}

\author{
Ronald Marentes-Culma, Luisa L. Orduz-Díaz ${ }^{(D)}$ and Ericsson Coy-Barrera * (D) \\ Laboratorio de Química Bioorgánica, Universidad Militar Nueva Granada, Cajicá 250247, Colombia; \\ u7500098@unimilitar.edu.co (R.M.-C.); luisa.orduz@unimilitar.edu.co (L.L.O.-D.) \\ * Correspondence: ericsson.coy@unimilitar.edu.co; Tel.: +57-1-6500000 (ext. 3270)
}

Received: 29 December 2018; Accepted: 19 February 2019; Published: 21 February 2019

check for updates

\begin{abstract}
A rapid and convenient biochemometrics-based analysis of several cereal-derived extracts was used to identify $n$-alkyl(enyl)resorcinols (AR) as antifungals against Fusarium oxysporum. Total AR content and liquid chromatography/mass spectrometry (LC-MS)-based profiles were recorded for each extract, in addition to their antifungal activity, to help integrate these chemical and biological datasets by orthogonal partial least squares regression. In this study, we developed and used a micro-scale amended medium (MSAM) assay to evaluate the in vitro mycelial growth inhibition at low amounts of extracts. Triticale husk-derived extracts had the highest AR content $(662.1 \mu \mathrm{g}$ olivetol equivalent/g dry extract), exhibiting $>79 \%$ inhibition at the highest doses $(10.0-1.0 \mu \mathrm{g} / \mu \mathrm{L})$. Correlation of the chemical and antifungal datasets using supervised metabolite profiling revealed that 5-n-nonadecanylresorcinol, 5- $n$-heneicosylresorcinol, and 5-n-tricosyl-resorcinol were the most active ARs occurring in cereal products from Colombia. Hence, we propose the biochemometrics-based approach as a useful tool for identifying AR-like antifungals against F. oxysporum.
\end{abstract}

Keywords: $5-n$-alkylresorcinols; cereals; Fusarium oxysporum; microscale amended medium assay; supervised metabolite profiling

\section{Introduction}

Cereals comprise some plant materials commonly called grasses-a merged name to designate those monocots of the Poaceae family. This family includes rice, wheat, rye, barley, oat, and other cereals, which represent the main source of food worldwide. Species within this family mostly produce a fruit called caryopsis (also grain or kernel). According to the Food and Agriculture Organization (FAO), 2610 million tons of cereals were produced in 2018, with wheat being the most prominent (754.1 million tons) [1]. In addition to their importance as a food supply, these grains are valuable materials for producing/accumulating several phytochemicals with potentially beneficial health effects, including reduced risk of diabetes, cancer, cardiovascular problems, chronic inflammation, neural degeneration, among other chronic disorders and diseases [2].

5-n-Alkyl(enyl)resorcinols (AR) are significant compounds found in cereals, which are specialized (or secondary) metabolites belonging to the phenolic lipids group, structurally composed by a meta-dihydroxy-substituted benzene ring and an alkyl (or alkenyl) chain at C-5 [3]. AR are commonly found in cereal grains, which so far have been their major source [3]. The highest AR contents have been reported in wheat bran, rye, and triticale, whereas maize, oats, and rice have smaller amounts $[4,5]$. ARs accumulate in the grain's intermediate layers (hyaline layer, integument, and intermediate pericarp), and can be extracted via maceration or other emerging methodologies, such as extraction using supercritical $\mathrm{CO}_{2}$ and methanol or ethanol as co-solvents [6,7]. 
Several studies have demonstrated different nutritional and biological properties of ARs, such as antioxidant, anti-cancer, antifungal effects, etc. [8-14]. However, their antifungal activity against some phytopathogens has not been widely investigated. Some studies have reported on the activity against phytopathogens of alkylresorcinols obtained from rye [9,15-17], durum wheat [18], mango peel [19,20], and barley [21,22], which targeted phytopathogenic species from the genus Fusarium, Penicillium, and Rhizoctonia due to their ability to infect several crops.

The genus Fusarium is a taxonomic group of filamentous, cosmopolitan fungi that can be both beneficial and harmful to plants, animals, and humans [23]. They are well-recognized pathogenic microorganisms that attack an extensive repertoire of plants and crops, causing damping-off, blotches, leaf boils, and dry rot in roots, stems, fruits, grains, and seeds [24]. In Colombia, four pathogenic species and 55 Fusarium-attacked plants have been recorded [25]. Fusarium oxysporum is the most important phytopathogen, which has been shown to infect $>100$ crop plants [26]. Several methods/strategies-biological and/or chemical-type controls-have therefore been attempted to control this species.

An alternative approach to control would be the use of naturally occurring compounds such as antifungal AR. However, the specific action or activity of individual and pure ARs remains unexplored due to isolation limitations associated with their chemical nature [22]. Therefore, the application of (un)targeted, supervised metabolomics for identifying a mixture's active compounds has recently extended significance due to its advantages. This method integrates both biological and chemical datasets to determine which compounds of a mixture are responsible for the biological activity; an approach called biochemometrics [27]. In our current research on antifungals of plant origin, we evaluated several cereal-derived extracts for their F. oxysporum growth inhibition effects using a microscale amended medium assay (MSAM) and a mass spectrometry-based biochemometrics approach. Using this approach we integrated the antifungal activity and AR-based chemical composition, as a strategy to identify bioactive AR in a set of extracts of different cereals from Colombia.

\section{Results}

\subsection{Standardization and AR Quantification}

Extraction from wheat bran using different solvents identified methanol as the best solvent for obtaining dry extracts (Table 1). On the other hand, acetone was the best solvent for extracting the highest AR amount (706.1 $\mu \mathrm{g}$ AR equivalent to olivetol per $\mathrm{g}$ of dry extract). Therefore, we chose acetone as a solvent for all other sample extractions.

Table 1. $n$-Alkyl(enyl)resorcinol (AR) extraction using different organic solvents.

\begin{tabular}{ccc}
\hline Solvent & Extraction Yield $(\% w / w)$ & Total AR Content $^{\text {a }}(\boldsymbol{\mu g}$ OE/g DE) \\
\hline Acetone & $3.9 \pm 0.2^{\mathrm{B}}$ & $706.1 \pm 23.2^{\mathrm{A}}$ \\
Methanol & $6.2 \pm 0.4^{\mathrm{A}}$ & $679.6 \pm 32.1^{\mathrm{AB}}$ \\
$n$-Hexane & $4.3^{\mathrm{B}} \pm 0.3^{\mathrm{B}}$ & $650.5 \pm 21.3^{\mathrm{B}}$ \\
Ethyl acetate & $3.1 \pm 0.2^{\mathrm{D}}$ & $510.7 \pm 35.5^{\mathrm{C}}$ \\
iso-Propanol & $3.5 \pm 0.1^{\mathrm{C}}$ & $497.2 \pm 28.6^{\mathrm{C}}$ \\
\hline
\end{tabular}

\footnotetext{
a Total AR Content in $\mu \mathrm{g}$ olivetol equivalent/g dry extract ( $\mu \mathrm{g}$ OE/g DE). All values are expressed as mean \pm standard deviation using data from three replicates. Different superscript capital letters reflect statistically significant differences between samples according to Tukey's test.
}

Within the analyzed samples, triticale husk (TH) extracts had the highest AR content, followed by wheat husk $(\mathrm{WH})$ extracts, while the remaining samples showed intermediate contents (Table 2). In general, triticale and wheat yielded the highest, while rice, sorghum, and oats yielded the lowest AR contents. 
Table 2. AR quantification for each processed sample, growth inhibition for each evaluated sample at three different concentrations, and their statistical classification.

\begin{tabular}{|c|c|c|c|c|c|c|c|}
\hline \multirow{2}{*}{ Samples } & \multirow{2}{*}{ Code } & \multirow{2}{*}{$\mathrm{CO}^{\mathrm{a}}$} & \multirow{2}{*}{$E^{\mathbf{b}}$} & \multirow{2}{*}{ TARC $^{c}$} & \multicolumn{3}{|c|}{ MGI $^{d}(\%)$} \\
\hline & & & & & $10.0 \mu \mathrm{g} / \mu \mathrm{L}$ & $1.0 \mu \mathrm{g} / \mu \mathrm{L}$ & $0.1 \mu \mathrm{g} / \mu \mathrm{L}$ \\
\hline Barley Husk & $\mathrm{BH}$ & Co & 0.12 & $24.7 \pm 0.5^{\mathrm{M}}$ & $74.8 \pm 1.5^{\mathrm{AB}}$ & $70.6 \pm 1.8^{\mathrm{BC}}$ & $12.9 \pm 1.8^{\mathrm{BCD}}$ \\
\hline Forage Oat Husk & $\mathrm{FOH}$ & $\mathrm{Cu}$ & 0.693 & $104.8 \pm 3.3^{\mathrm{IJ}}$ & $36.4 \pm 11.3^{\mathrm{EF}}$ & $17.8 \pm 1.6^{\mathrm{FG}}$ & $19.1 \pm 5.6^{\mathrm{BC}}$ \\
\hline Rice Husk & $\mathrm{RH}$ & $\mathrm{Co}$ & 0.509 & $115.8 \pm 4.2^{\mathrm{I}}$ & $33.1 \pm 1.7^{\mathrm{EFG}}$ & $16.2 \pm 6.2 \mathrm{FG}$ & $11.7 \pm 1.4^{C D}$ \\
\hline Triticale Husk & $\mathrm{TH}$ & $\mathrm{Cu}$ & 1.659 & $662.1 \pm 20.4^{\mathrm{A}}$ & $82.5 \pm 0.3^{\mathrm{AB}}$ & $79.4 \pm 1.6^{\mathrm{AB}}$ & $18.8 \pm 3.0^{\mathrm{BC}}$ \\
\hline Wheat Husk & WH & $\mathrm{Cu}$ & 1.734 & $541.9 \pm 24.7^{\text {B }}$ & $56.6 \pm 2.6^{C D}$ & $21.3 \pm 0.2^{\mathrm{DEF}}$ & $26.5 \pm 1.2^{\mathrm{B}}$ \\
\hline Pearl Barley & PB & Co & 0.666 & $156.3 \pm 2.4^{\mathrm{GH}}$ & $13.5 \pm 2.3^{\mathrm{HI}}$ & $11.5 \pm 0.4^{\mathrm{G}}$ & $7.5 \pm 7.7^{C D}$ \\
\hline Certificate Oat Husk & $\mathrm{COH}$ & $\mathrm{Co}$ & 0.451 & $81.8 \pm 3.7^{\mathrm{K}}$ & $85.6 \pm 0.2^{\mathrm{A}}$ & $80.7 \pm 0.2^{\mathrm{A}}$ & $80.7 \pm 1.4^{\mathrm{A}}$ \\
\hline Certificate Oat Caryopsis & $\mathrm{COC}$ & Co & 0.596 & $86.2 \pm 3.0 \mathrm{JK}$ & $75.1 \pm 2.9 \mathrm{AB}$ & $65.5 \pm 0.1^{\mathrm{C}}$ & $19.2 \pm 1.2^{\mathrm{BC}}$ \\
\hline Forage Corn Flour & FCF & Co & 0.724 & $103.9 \pm 4.4^{\mathrm{IJ}}$ & $47.7 \pm 2.7^{\mathrm{DE}}$ & $19.9 \pm 0.8^{\mathrm{EFG}}$ & $9.9 \pm 1.1 \mathrm{CD}$ \\
\hline Oats Flakes & $\mathrm{OF}$ & $\mathrm{Co}$ & 0.591 & $85.1 \pm 5.2 \mathrm{JK}$ & $36.5 \pm 5.7 \mathrm{EF}$ & $23.0 \pm 1.2 \mathrm{DEF}$ & $8.2 \pm 0.7^{C D}$ \\
\hline Barley Caryopsis & $\mathrm{BC}$ & Co & 0.648 & $117.5 \pm 2.0^{\mathrm{I}}$ & $25.0 \pm 3.2 \mathrm{FGH}$ & $18.9 \pm 1.0^{\mathrm{EFG}}$ & $11.6 \pm 0.5^{\mathrm{CD}}$ \\
\hline Forage Oat Caryopsis & FOC & $\mathrm{Cu}$ & 0.796 & $139.2 \pm 2.5^{\mathrm{H}}$ & $69.9 \pm 0.6^{\mathrm{BC}}$ & $16.5 \pm 3.0^{\mathrm{FG}}$ & $11.7 \pm 0.1 \mathrm{CD}$ \\
\hline Rice Caryopsis & $\mathrm{RC}$ & Co & 0.251 & $56.6 \pm 1.4^{\mathrm{L}}$ & $3.9 \pm 0.4^{\mathrm{I}}$ & $0.0 \pm 0.0^{\mathrm{H}}$ & $0.0 \pm 0.0^{\mathrm{D}}$ \\
\hline Sorghum Caryopsis & SC & Co & 0.146 & $26.2 \pm 0.7^{\mathrm{M}}$ & $19.5 \pm 0.3 \mathrm{GH}$ & $16.2 \pm 0.8^{\mathrm{FG}}$ & $10.7 \pm 6.6^{C D}$ \\
\hline Soy Seed & SS & $\mathrm{Cu}$ & 1.039 & $168.2 \pm 2.0^{\mathrm{EFG}}$ & $77.4 \pm 0.7^{\mathrm{AB}}$ & $25.2 \pm 0.2 \mathrm{DEF}$ & $13.7 \pm 1.7^{\mathrm{BCD}}$ \\
\hline Triticale Caryopsis & $\mathrm{TC}$ & $\mathrm{Cu}$ & 0.648 & $185.4 \pm 6.9^{\mathrm{E}}$ & $78.5 \pm 3.7^{\mathrm{AB}}$ & $75.7 \pm 4.7 \mathrm{AB}$ & $18.4 \pm 2.7^{\mathrm{BC}}$ \\
\hline Wheat Caryopsis & WC & $\mathrm{Cu}$ & 0.688 & $177.5 \pm 4.6^{\mathrm{EF}}$ & $76.9 \pm 1.3^{\mathrm{AB}}$ & $63.4 \pm 2.1^{C}$ & $11.9 \pm 3.9^{C D}$ \\
\hline Wheat flour & WF & Co & 1.314 & $363.0 \pm 16.8^{C}$ & $77.2 \pm 4.3^{\mathrm{AB}}$ & $30.1 \pm 4.0^{\mathrm{D}}$ & $8.4 \pm 0.1 \mathrm{CD}$ \\
\hline White Corn Flour & WCF & Co & 1.131 & $162.8 \pm 4.6^{\mathrm{FG}}$ & $52.0 \pm 2.1^{\mathrm{D}}$ & $15.9 \pm 0.3^{\mathrm{FG}}$ & $7.4 \pm 5.5 \mathrm{CD}$ \\
\hline Yellow Corn & YC & $\mathrm{Cu}$ & 1.131 & $215.7 \pm 3.2^{\mathrm{D}}$ & $75.2 \pm 0.7 \mathrm{AB}$ & $27.6 \pm 1.9 \mathrm{DE}$ & $15.5 \pm 0.5^{\mathrm{BC}}$ \\
\hline Yellow Corn Flour & YCF & $\mathrm{Co}$ & 1.093 & $157.7 \pm 5.6^{\mathrm{FGH}}$ & $46.0 \pm 5.6^{\mathrm{DE}}$ & $23.1 \pm 2.1 \mathrm{DEF}$ & $18.6 \pm 6.3^{\mathrm{BC}}$ \\
\hline
\end{tabular}

${ }^{a}$ Cereal origin (CO): $\mathrm{Co}=$ commercially purchased in Bogotá, Colombia, $\mathrm{Cu}=$ cultivated in the Nueva Granada campus, Cajicá, Colombia; ${ }^{\mathrm{b}}$ Extraction Yield (EY) in \%w/w; ${ }^{\mathrm{c}}$ Total $5-n$-alk(en)ylresorcinol (AR) Content (TARC) in $\mu \mathrm{g}$ Olivetol equivalent/g dry extract (DE); ${ }^{\mathrm{d}}$ mycelial growth inhibition (MGI); data expressed as mean \pm standard deviation using three replicates. Different superscript capital letters reflect statistically significant differences between samples according to Tukey's test.

\subsection{Inhibition of Mycelial Growth on F. oxysporum}

For the resultant 21 extracts, in vitro mycelial growth inhibition (MGI) against $F$. oxysporum was evaluated using the MSAM assay. Table 2 lists the MGI results for each extract and the corresponding doses. The data showed that the inhibition was dose-dependent, with values ranging $0.0-83.0 \%$ at 0.1-10.0 $\mu \mathrm{g} / \mu \mathrm{L}$ doses, also exhibiting some significant differences between themselves $(p<0.05)$. Certificate oat husk $(\mathrm{COH})$ samples showed the highest inhibition percentage, exceeding $80 \%$ in all three treatments. Triticale husk (TH) and triticale caryopsis (TC) also showed high inhibition percentages, while exhibiting a dose-dependent behavior. On the other hand, rice caryopsis (RC) samples had a lower inhibition percentage; a response only seen at the highest concentration (i.e., $10.0 \mu \mathrm{g} / \mu \mathrm{L}$ ).

\subsection{Liquid Chromatography coupled to Electrospray Ionization Mass Spectrometry (LC-ESIMS) Analysis}

Positive ion mode did not give satisfactory LC-ESIMS profiles through electrospray ionization due to the phenolic nature of the ARs (data not shown). LC-ESIMS profiles (in negative ion mode) provided better information regarding composition differences between samples (Figure 1). A chromatographic method was particularly developed in this study for increasing AR's separation procedure selectivity using reverse phase liquid chromatography. Due to the amphipathic nature of AR (very structurally related, differentiated by their side chains' lengths and substitutions), this separation involved the addition of isopropanol (IPA) as a component of the organic modifier mixture (as eluent B, mixing IPA:MeOH (8:2)) as well as aqueous $\mathrm{MeOH}$ (as eluent A, mixing $\mathrm{MeOH}: \mathrm{H}_{2} \mathrm{O}(8: 2)$ ), using gradient elution. This chromatographic method allowed the elution of AR compounds at 15-19 min (indicated as "AR zone", Figure 1a), differentiated/separated from other polar and non-polar components, e.g., sugars, phenolics, organic acids, and triglycerides, among others (data not shown), which were also present in the extracts. A holistic view of all chromatograms is depicted in the respective heat map (Figure 1b), where the metabolic fingerprints exhibited remarkable differences in some samples but similarities in other zones between extracts. Triticale caryopsis-derived extracts exhibited the highest 
number of AR compounds. Putative identification at level three [28,29] is shown in Table 3. Twelve main AR-like compounds were then detected and identified (compounds 1-12) [3,30].

(a)

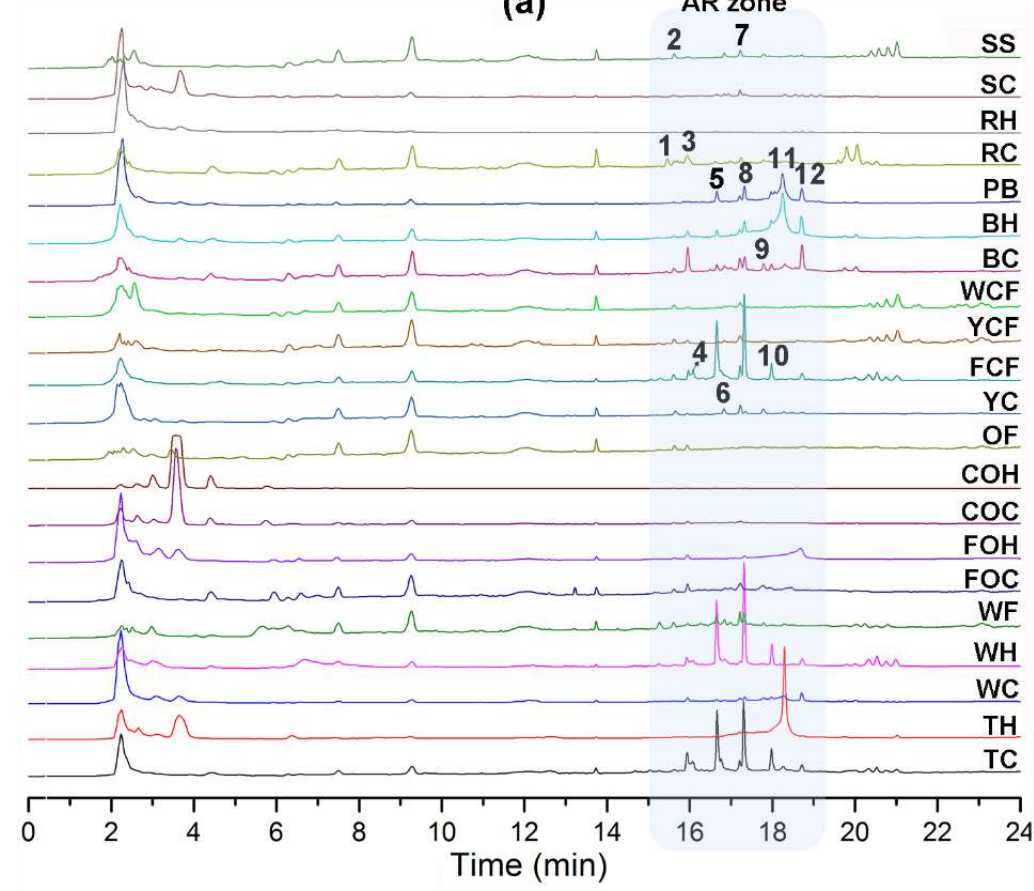

(b)

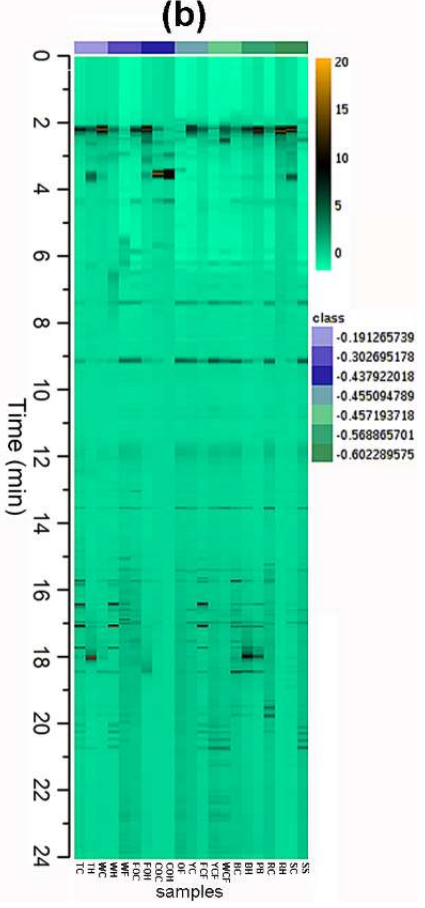

Figure 1. (a) Liquid Chromatography coupled to electrospray ionization mass spectrometry (LC-ESIMS) profiles; samples abbreviation according to Table 2; n-alkyl(enyl)resorcinols (AR) zone within chromatogram is highlighted in light blue box; bold numbers indicate the annotated AR according to Table 3; (b) LC-ESIMS data-derived heatmap using the Ward clustering algorithm and Euclidean distances; spots correspond to each detected compound by LC-ESIMS in the negative ion mode.

\subsection{Peak Annotation}

In order to ensure a robust annotation and identification of AR-related metabolites, three mass spectrometry (MS)-based analyses were additionally performed on raw extracts: (1) high-resolution mass spectrometry using a quadrupole-time-of-flight (QToF) tandem mass analyzer and electrospray ionization (HRESIMS) in negative ion mode coupled to an Ultra-Fast Liquid Chromatography (UFLC) system, (2) low-resolution mass spectrometry using a single quadrupole mass analyzer and electrospray (LRESIMS) ionization in negative ion mode coupled to a UFLC system, and (3) electron-impact mass spectrometry (EIMS) using a quadrupole mass analyzer coupled to a gas chromatography (GC) system after derivatization using $\mathrm{N}$-methyl- $\mathrm{N}$-trimethylsilyltrifluoro-acetamide (MSTFA). Compilation of these data (Table A1) resulted in better peak annotation (Table 3). Thus, $[\mathrm{M}-\mathrm{H}]^{-}$and $[2 \mathrm{M}-\mathrm{H}]^{-}$ adducts that resulted from low-resolution (LR) and high-resolution (HR) ESIMS analyses, ensured a correct assignment through molecular ions and exact mass in agreement with the molecular formula for the identified metabolites (error $<4$ ppm). Alkenylresorcinols such as 1, 4, 6, and $\mathbf{1 1}$ exhibited ions in HRESIMS spectra, involving losses in the side chain by $\alpha$-cleavage at double bonds (e.g., $\mathrm{C}_{2} \mathrm{H}_{5} \mathrm{OH}, \mathrm{C}_{2} \mathrm{H}_{2}$, and $\mathrm{C}_{10} \mathrm{H}_{16}$ ). The resorcinol moiety of compounds 1-12 was also established after derivatization using $N$-methyl- $N$-trimethylsilyl-trifluoroacetamide activated II $^{\circledR}$ (MSTFA), following the protocol previously described [31]. All compounds shared very similar fragmentation patterns to silylated AR, indicating the homologous nature of all identified compounds [3]. Thus, the resulting trimethylsilyl (TMS) ether derivatives were analyzed using GC/EIMS, and the characteristic fragment at $m / z 268$ (base peak) was a distinctive signal for the di-O-silylated 1,3-dihydroxytropylium cation $\left(\left[(\mathrm{TMSO})_{2} \mathrm{C}_{6} \mathrm{H}_{4} \mathrm{CH}_{2}\right]^{+}\right.$), as well as fragments at $m / z 281,310$, and 341 , which are very common for ARs [32,33]. According to the quasi-molecular ions recorded in LR and HRESIMS spectra, the respective 
molecular ion for each di-O-silylated derivative of compounds 1-12 was consequently detected $\left(\left[\mathrm{M}+(\mathrm{TMS})_{2}\right]^{+}\right)$. Differences between the fragment at $m / z 268$ and molecular ion, indicated the particular length for the side chain, which in turn involved consecutive losses of $\mathrm{CH}_{2}$ fragments [30,31].

Table 3. Annotated $5-n$-alk(en)ylresorcinols homologues in acetone extracts, using LC-ESIMS (in negative ion mode).

\begin{tabular}{|c|c|c|c|c|c|c|}
\hline No & $\begin{array}{c}\mathbf{R t} \\
(\mathrm{min})^{\mathrm{a}}\end{array}$ & $\begin{array}{c}{[\mathrm{M}-\mathrm{H}]^{-}} \\
(\mathrm{m} / \mathrm{z})^{\mathrm{b}}\end{array}$ & $\begin{array}{l}\text { Error } \\
\text { (ppm) }\end{array}$ & $\begin{array}{l}\text { Molecular } \\
\text { Formula }{ }^{c}\end{array}$ & Homologue & Name \\
\hline 1 & 15.4 & 389.3048 & -1.80 & $\mathrm{C}_{25} \mathrm{H}_{42} \mathrm{O}_{3}$ & $\mathrm{C} 19: 1, \mathrm{OH}$ & 5- $n$-(hydroxynonadecenyl)resorcinol \\
\hline 2 & 15.6 & 455.3896 & 1.54 & $\mathrm{C}_{31} \mathrm{H}_{52} \mathrm{O}_{2}$ & C25:2 & 5 - $n$-(pentacosadienyl)-resorcinol \\
\hline 3 & 15.9 & 347.2956 & 1.73 & $\mathrm{C}_{23} \mathrm{H}_{40} \mathrm{O}_{2}$ & $\mathrm{C} 17$ & 5 - $n$-heptadecylresorcinol \\
\hline 4 & 16.1 & 373.3113 & 1.88 & $\mathrm{C}_{25} \mathrm{H}_{42} \mathrm{O}_{2}$ & C19:1 & 5 - $n$-nonadecenylresorcinol \\
\hline 5 & 16.7 & 375.3269 & 1.60 & $\mathrm{C}_{25} \mathrm{H}_{44} \mathrm{O}_{2}$ & C19 & 5-n-nonadecanylresorcinol \\
\hline 6 & 16.9 & 401.3413 & -1.49 & $\mathrm{C}_{27} \mathrm{H}_{46} \mathrm{O}_{2}$ & C21:1 & 5- $n$-henicosenylresorcinol \\
\hline 7 & 17.2 & 445.3693 & 2.69 & $\mathrm{C}_{29} \mathrm{H}_{50} \mathrm{O}_{3}$ & $\mathrm{C} 23, \mathrm{Oxo}$ & 5-n-(oxotricosanyl)-resorcinol \\
\hline 8 & 17.4 & 403.3586 & 2.48 & $\mathrm{C}_{27} \mathrm{H}_{48} \mathrm{O}_{2}$ & $\mathrm{C} 21$ & 5- $n$-henicosylresorcinol \\
\hline 9 & 17.7 & 415.3201 & -2.65 & $\mathrm{C}_{27} \mathrm{H}_{44} \mathrm{O}_{3}$ & C21:1, Oxo & 5- $n$-(oxoheneicosenyl)-resorcinol \\
\hline 10 & 18.0 & 431.3903 & 3.25 & $\mathrm{C}_{29} \mathrm{H}_{52} \mathrm{O}_{2}$ & $\mathrm{C} 23$ & 5 - $n$-tricosylresorcinol \\
\hline 11 & 18.3 & 479.3899 & 2.09 & $\mathrm{C}_{33} \mathrm{H}_{52} \mathrm{O}_{2}$ & C27:4 & 5- $n$-heptacosatetraenylresorcinol \\
\hline 12 & 18.8 & 459.4216 & 3.05 & $\mathrm{C}_{31} \mathrm{H}_{56} \mathrm{O}_{2}$ & $\mathrm{C} 25$ & 5-n-pentacosylresorcinol \\
\hline
\end{tabular}

${ }^{\mathrm{a}} \mathrm{R}_{\mathrm{t}}=$ retention time (in min); ${ }^{\mathrm{b}}$ high-resolution mass spectrometry using a quadrupole-time-of-flight (QToF) tandem mass analyzer and electrospray ionization in negative ion mode coupled to an Ultra-Fast Liquid Chromatography (UFLC) system; ${ }^{\mathrm{C}}$ molecular formula deduced from analyses of mass spectra data (see Table A1).

\subsection{Multivariate Analysis}

LC-HRESIMS data (in negative mode) were examined using principal components analysis (PCA, Figure $2 \mathrm{a}$ ). The resulting model explained that $80 \%$ of the data's total variance was from the first three components. Using a hierarchical clustering analysis (HCA) on PCA data points (Figure 2b), four groups were identified.

A single-Y orthogonal partial least squares (OLPS) analysis was therefore performed to visualize the relationship between LC-MS profiles and total AR contents. The score plot (Figure 3a) showed a good AR content-related distribution. Furthermore, the S-line projection (Figure 3b) was then constructed to determine those variables/signals obtained in the LC-ESIMS analysis (in negative mode) and their relation to the AR total content. Three signals were correlated to AR-rich samples eluted at 15-19 min. Similarly, another OPLS model was built to integrate LC-ESIMS profiles and inhibition data, to determine the plausible relationship between the chemical composition and antifungal activity (Figure 3c). Inhibition at a higher dose $(10 \mu \mathrm{g} / \mu \mathrm{L})$ was used because all samples inhibited mycelial growth at this dose to different extents, thus incorporating a better distribution depending on growth inhibition. Respective $S$-line projection identified three activity-correlating signals (Figure 3d).

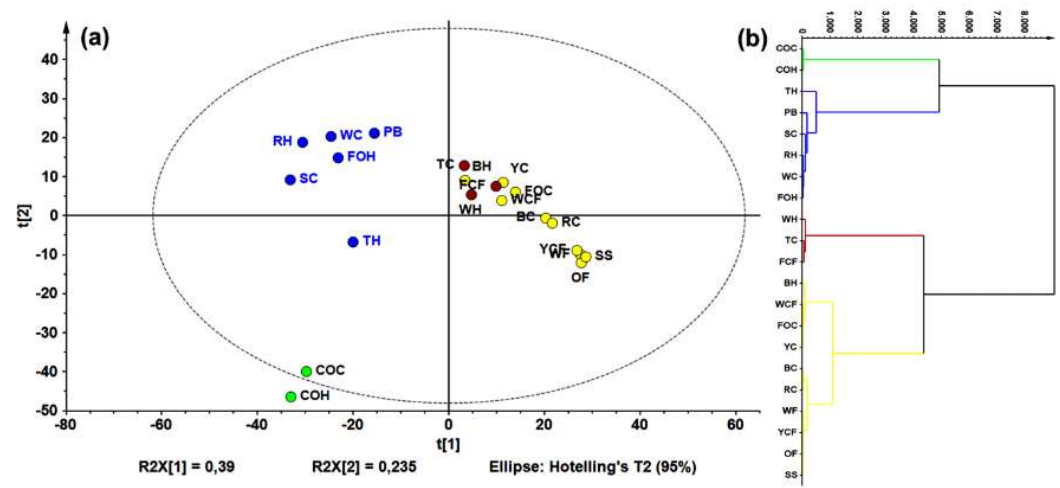

Figure 2. Principal component analysis (PCA) on liquid chromatography-mass spectrometry (LC-MS) data for all samples. (a) Principal component 1 (PC1) vs. PC2 score plot $\left(R^{2} x_{\text {cum }}=0.625\right)$, colors according to hierarchical clustering analysis (HCA); and (b) HCA-derived dendrogram over PCA data. 

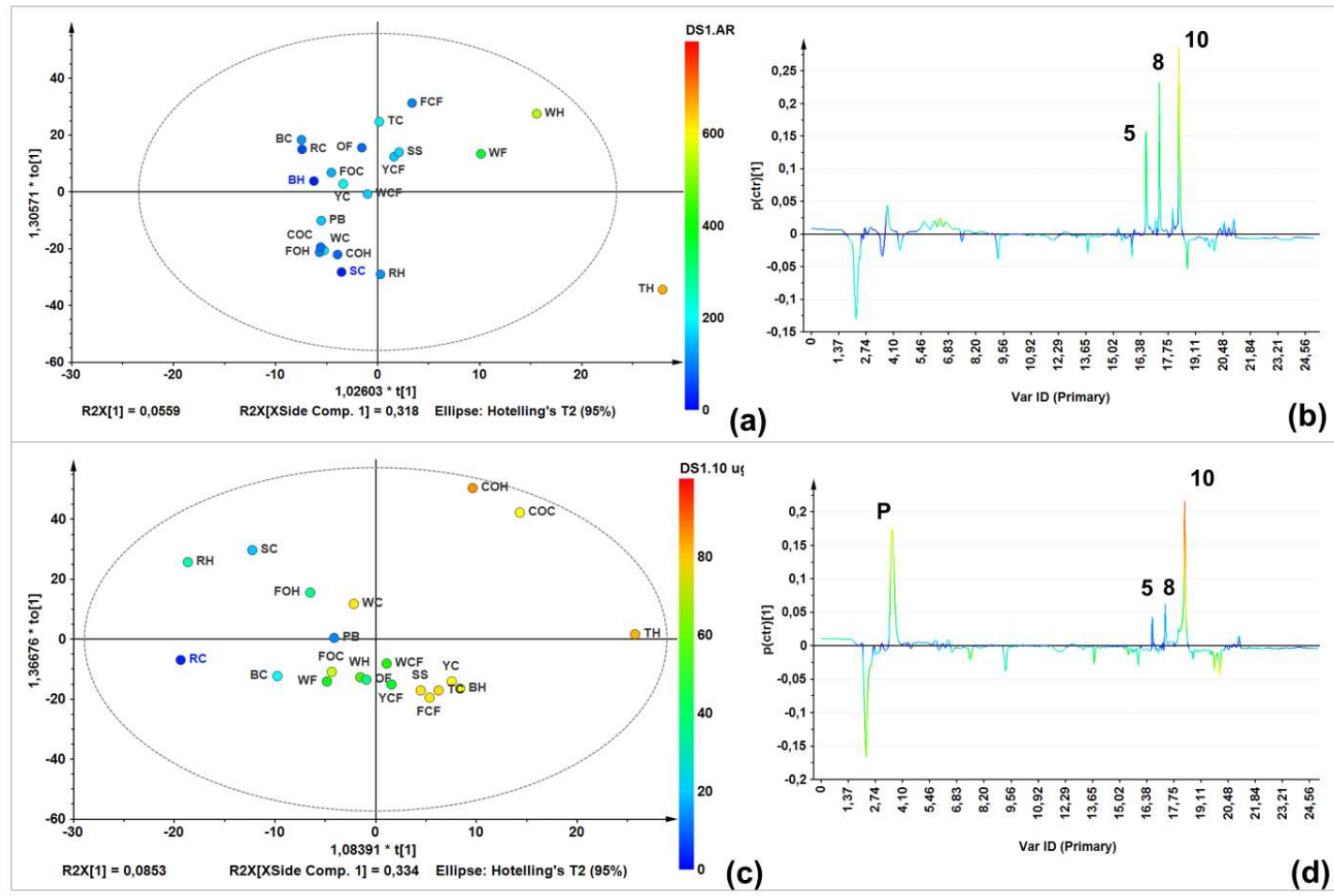

Figure 3. Targeted analysis using supervised statistics (biochemometrics). (a) Single-Y orthogonal partial least-squares regression (OPLS)-derived score plot on LC-MS (in negative ion mode) data using total AR content (TARC) as supervision variable; (b) S-line projection on LC-MS (in negative ion mode) data and TARC values; (c) Single-Y OPLS-derived score plot on LC-MS (in negative ion mode) data using antifungal activity at $10 \mu \mathrm{g} / \mu \mathrm{L}$ as supervision variable; and (d) S-line projection on LC-MS (in negative ion mode) data and antifungal activity at $10 \mu \mathrm{g} / \mu \mathrm{L}$.

\section{Discussion}

Among the solvents used for AR extraction, acetone extracted the highest amount of target compounds compared to the other three solvents according to Tukey's test $(p<0.05)$. Although there is no statistical significance compared to methanol, acetone was chosen due to its nature-intermediate-to-high polarity, which matches the amphipathic characteristic of ARs-and ability to extract more diverse ARs [30]. Acetone also has low environmental impact, and is therefore more easily removed from the extract matrix [34,35].

Colorimetric AR quantification indicated that all extracts contain these metabolites at different levels (i.e., 24-660 $\mu$ g olivetol equivalent (OE)/g dry extract (DE) range), although some have been reported to be absent [36]. The highest AR content was found in triticale husk (TH) $(662.1 \mu \mathrm{g} \mathrm{OE} / \mathrm{g}$ $\mathrm{DE})$, followed by wheat husk (WH) $(541.7 \mu \mathrm{g} \mathrm{OE} / \mathrm{g} \mathrm{DE})$. While in kernels, the triticale caryopsis (TC) (185.4 $\mu \mathrm{g}$ OE/g DE) and wheat caryopsis (WH) (177.5 $\mu \mathrm{g} \mathrm{OE} / \mathrm{g}$ DE) had higher AR contents (Table 2). These metabolites have been found to accumulate at higher levels in different layers of the caryopsis, such as the hyaline layer, testa, and inner pericarp [6], while there is no record of them existing in husk. Consistently, Athukorala et al. [7] reported higher AR contents in a triticale (a wheat-rye hybrid) cultivar (700 $\mu \mathrm{g} / \mathrm{g}$ dry bran) compared to wheat, with the highest content recorded in bran rye $(750 \mu \mathrm{g} / \mathrm{g}$ dry bran). Lower AR contents were found in other rye products [37]. In addition, triticale caryopsis had the highest variety of these metabolites, according to the negative-mode LC-ESIMS analysis. Compounds such as $\mathrm{C}_{17}, \mathrm{C}_{19}, \mathrm{C}_{21}, \mathrm{C}_{23}$, and $\mathrm{C}_{25}$-type alkylresorcinols were then recorded [38-40]. In the present study, cultivated soybean seeds (SS; used for human consumption) also exhibited AR presence. Such compounds are not exclusive to the Poaceae species, since some Fabaceae plants contain AR, which has been reported in Ononis genus [41]. 
Regarding unsupervised analysis on LC-ESIMS data, four clusters were found according to HCA (Figure 2b), which are shown in a two-component plots (Figure 2a). Within the group possessing the highest variance compared to the others (green), there was a group involving commercial oats samples (caryopsis and husk); a second (red) comprised rice caryopsis, barley, wheat flour, and oat flakes; the blue group contained samples with weak inter-relations such as triticale husk, forage oats, and rice; and the yellow group involved triticale and forage oat caryopsis. Wheat flour had a lower AR content compared to the other samples (e.g., husk and caryopsis wheat), this is mainly caused by the fact that during refining, grinding, and sieving processes, too much of the pericarp and husk is eliminated. Similar condition can occur with corn flour, which can explain these samples clustering in different groups compared to other extracts from the same species. This statistically-based comparison of chemical compositions between extracts can rationalize the observed activity against $F$. oxysporum. In fact, a comparison between the LC-ESIMS profiles and total AR contents (through construction of a single-Y OLPS) indicated a composition-related distribution associated with their AR content. Thus, samples with the lowest AR content were in the third quadrant, while those with the highest content clustered in the first quadrant. The respective $S$-line projection revealed three features (i.e., LC-ESIMS signals) that correlated with total AR contents of all extracts. These features are then related to compounds 5, 8, 10 (Figure 3b).

In the context of evaluating extracts against $F$. oxysporum using the MSAM method, MGI could be assessed even when extract amounts are low, which is a particular limitation during screening initiatives as well as for validation purposes, due to the lack of replicates and a suitable method for evaluating MGI at a microscale level. The MSAM protocol (using low amounts of medium and inputs) produced reproducible results for the activity, generating a smaller quantity of waste, which is the common problem in the antifungal-amended medium protocol in petri dishes.

Some experimental studies have indicated that plants synthesize ARs to create a chemical barrier for resisting fungal attacks [42-44]. Therefore, the antifungal activity of these products is attributed to the presence of ARs. According to MSAM assays against F. oxysporum, the highest activity was found for certificate oat husk $(\mathrm{COH})$, which exhibited $>80 \%$ inhibition in all three doses. However, these samples were purchased with commercial certification for starting a crop (no human/animal consumption). These materials are treated with different commercial antifungals [45], which guarantee caryopsis protection to various post-harvest products that affect pathogens such as Fusarium, Rhizoctonia, Penicillium, and Aspergillus $[15,17]$. In fact, this certified oat caryopsis and husk were previously treated with phenylpyrrole fludioxonil, which we used as an internal standard. Due to the above fact, the high inhibition was therefore attributed to this agent being extracted by acetone and being active within the extract. The LC-ESIMS profile of $\mathrm{COH}$ prominently differed from other samples (even from other oat samples), which was evident from the unsupervised analysis by its higher variance (Figure 2a). Caution is therefore advised when polluted botanical extracts are evaluated in order to avoid false positives.

The results in Table 2 agree with those previously published [9], where a mixture of $C_{13}-C_{27}$ saturated 5- $n$-alkylresorcinols was tested against three phytopathogens (F. culmorum (WG Sm.) Sacc., Rhizoctonia solani JG Kühn, and R. cerealis EP Hoeven). The authors found that this mixture was inhibitory at different levels; phytopathogens were inhibited at $10-20 \mu \mathrm{g} / \mu \mathrm{L}$, with F. culmorun being the most treatment resistant. When comparing our present results, we found more bioactivity in some test extracts, where the highest growth inhibition was observed at $1.0 \mu \mathrm{g} / \mu \mathrm{L}$, whereas previous studies achieved similar inhibition at $5-10 \mu \mathrm{g} / \mu \mathrm{L}$ [9]. Triticale (husk and caryopsis) exhibited the highest inhibitory effect at 10.0 and $1.0 \mu \mathrm{g} / \mu \mathrm{L}$ (75-83\% inhibition range). Triticale husk had the highest AR concentration (Table 2), whereas triticale caryopsis did not present a high AR content compared to other samples, however, it contained the highest number of identified compounds. From the MS-based identification, a single compound with several unsaturations was found in triticale (identified as $5-n$-heptacosatetraenylresorcinol, $\mathrm{C}_{27: 4}$ ), which has also been reported in rye, the triticale progenitor [3]. 
In this context, information regarding extract composition and antifungal activity separately did not reveal an association with presence/absence of bioactive ARs. Therefore, integrating the mycelial growth inhibition (dependent) with LC-ESIMS (independent) data as a tool for identifying antifungal components, the subsequent biochemometrics-based analysis through the internal cross-validated construction of a single- $Y$ OPLS model (Figure 3c) evidenced some correlation based on bioactivity $\left(R^{2} X_{\text {cum }}=0.719\right)$. The respective $S$-line displayed graphically the influence and correlation of loadings against the dependent variable. For this biochemometrics-based model, the upper quadrant of the $S$-line contributed the most to biologically differentiating more versus less active extracts. Thus, 5-n-nonadecanylresorcinol (5), 5- $n$-henicosylresorcinol (8), and 5- $n$-tricosylresorcinol (10) were identified as possessing the highest contribution to the observed high mycelial growth inhibition. Compound 10 exhibited the highest correlation value in S-line (ca. 80\%) (Figure 3b). These identified chemical features are in agreement with a previous study describing that saturated and longer-chain AR may retain antifungal activity for longer, since some phytopathogenic fungi have the capacity to metabolize relatively shorter chain alkylresorcinols, transforming them into less toxic compounds [15]. These compounds can be consequently considered as promising antifungals for inclusion in further studies to validate these findings. Other phenolics (signals within 2-14 min) exhibit no correlation with antifungal activity. In fact, the abundant compound at $2.2 \mathrm{~min}$ (ferulic acid, $m / z 193[\mathrm{M}-\mathrm{H}]^{-}$) was present in samples with lower activity, indicating no relationship with antifungal action. In contrast, a compound marked as P (3.7 min, Figure 3d) was identified as the phenylpyrrole fludioxonil $(\mathrm{m} / \mathrm{z} 247$ $\left.[\mathrm{M}-\mathrm{H}]^{-}\right)$, the fungicidal ingredient used to protect the certified oat caryopsis. This reference material with this fungicide were used as internal standards and, as observed in the respective $S$-line (Figure 3d), this compound correlated with antifungal activity but not AR contents. These facts therefore confirm the usefulness of this biochemometric model for AR-like antifungals identification.

\section{Material and Methods}

\subsection{Fungal and Plant Material}

Plant materials of some cereals were obtained from several places in Colombia. Caryopsis and husk of barley, triticale, yellow corn, and wheat were gathered from an experimental crop at Nueva Granada Campus in Cajicá, Colombia; caryopsis and husk of rice, oat, pearl barley, soy, and sorghum, wheat flour, corn (forage, white and yellow) flour, and oat flakes were purchased from different marketplaces in Bogotá, Colombia. All aforementioned materials were ensured to be free of pesticide traces based on the organic cultivation protocol implemented for human/animal consumption. In addition, certificate oat material (husk and caryopsis), previously treated with fludioxonil, was also purchased from a marketplace in Bogotá, Colombia for use as reference material. The Fusarium oxysporum strain was obtained from a Cape gooseberry (Physalis peruviana) crop, preserved on Whatman paper $\# 1$ at $-20{ }^{\circ} \mathrm{C}$, and reactivated in Potato Dextrose Agar (PDA) at full concentration before use.

\subsection{Extracts Standardization and Total AR Quantification}

All kernel samples were grinded in a Waring WGS30 grinder machine (Waring Commercial, Stamford, CT, USA), and the husk was separated from the flour using a stainless steel sifter $(18 \mathrm{~cm}$ diameter, mesh 40) prior to the extraction. The best AR extraction solvent was determined as follows: a 24-h maceration extraction was carried out on wheat bran $(1 \mathrm{~g})$ with different solvents $(10 \mathrm{~mL}$; $n$-hexane, ethyl acetate, isopropanol, acetone, and methanol). The resulting mixture was then filtered and concentrated under reduced pressure to obtain the unfractionated, crude extract in each solvent.

Total AR content (TARC) was determined by the colorimetric quantification method reported by Sampietro et al. [46], using the Diazonium salt Fast Blue ${ }^{\circledR}$ RR $\left(F B R R^{\circledR}\right)$ with some modifications. Briefly, a working solution was prepared at $1: 5$ ratio with methanol (stock $0.5 \mathrm{mg} / \mathrm{mL} \mathrm{FBRR}{ }^{\circledR}$ ), and a solution to $5 \mathrm{mg} / \mathrm{mL}$ of the samples previously prepared. An aliquot of extract solution $(20 \mu \mathrm{L})$ was 
added, FBRR ${ }^{\circledR}$ working solution $(2 \mathrm{~mL})$ and $10 \%$ sodium carbonate $\left(\mathrm{Na}_{2} \mathrm{CO}_{3} ; 10 \mu \mathrm{L}\right)$ were dispensed into spectrophotometric cells. These cells were incubated for $20 \mathrm{~min}$ at room temperature and the absorbance was measured on a Genesys 20 spectrophotometer (Thermo Scientific, Waltham, MA, USA) at $480 \mathrm{~nm}$. Total AR content was then calculated from a previously constructed calibration curve using olivetol (5-pentylresorcinol) as standard. The selected solvent (i.e., acetone) was allowed to remove AR from other samples using $60 \mathrm{~g}$ of plant material for the respective extract preparation. Thus, the procedure described previously for wheat bran was therefore performed for all samples. TARC values were expressed as $\mu \mathrm{g}$ olivetol equivalent per g dried extract ( $\mu \mathrm{g} \mathrm{OE} / \mathrm{g} \mathrm{DE}$ ).

\subsection{Extraction and Chemical Analyses for Metabolite Profiling}

\subsubsection{Preparation of AR-Rich Extracts from Different Cereals}

Once the extraction procedure was standardized/optimized as described in Section 4.2, 21 different dry, ground cereal materials were used for chemical analyses. A 24-h maceration extraction using acetone $(10 \mathrm{~mL})$ was performed on cereal material $(1 \mathrm{~g})$. After extraction, the resulting mixture was filtered and concentrated under reduced pressure to obtain the unfractionated, crude AR-rich extracts. All extracts were stored at $-20^{\circ} \mathrm{C}$ until respective use in chemical analyses and antifungal assay.

\subsubsection{High Performance Liquid Chromatography-Electrospray Ionization-Mass Spectrometry} (LC-ESI-MS) Analysis

All extracts were analyzed using Reverse Phase Ultra-Fast Liquid Chromatography coupled to a microTOFQ II mass spectrometer (Bruker, Billerica, MA, USA). A Kinetex ${ }^{\circledR}$ column $(150 \times$ $4.6 \mathrm{~mm}, 2.6 \mu \mathrm{m}$ ) was used for analysis at $0.6 \mathrm{~mL} / \mathrm{min}$ using the mixtures $\mathrm{MeOH}: \mathrm{H}_{2} \mathrm{O}(8: 2)(\mathrm{A})$ and isopropanol: $\mathrm{MeOH}(3: 7)(\mathrm{B})$ in a gradient method $(0-2 \min 0 \% \mathrm{~B}, 14-23 \min 100 \% \mathrm{~B}$, and $25-30 \min 0 \%$ B). Electrospray ionization interface (ESI) was operated in a negative ion mode (scan 100-2000 $\mathrm{m} / \mathrm{z}$ ), desolvation line temperature at $250{ }^{\circ} \mathrm{C}$, nitrogen as nebulizer gas at $1.5 \mathrm{~L} / \mathrm{min}$, drying gas at $8 \mathrm{~L} / \mathrm{min}$, quadrupole energy at $7.0 \mathrm{eV}$, and collision energy $14 \mathrm{eV}$.

Extracts were also analyzed by Reverse Phase Ultra-Fast Liquid Chromatography coupled to a Diode Array Detector (UFLC-DAD) on a Prominence system (Shimadzu, Columbia, MD, USA), coupled to a Shimadzu LC2020 mass spectrometerA Kinetex ${ }^{\circledR}$ column $(150 \times 4.6 \mathrm{~mm}, 2.6 \mu \mathrm{m})$ was used for analysis at $0.6 \mathrm{~mL} / \mathrm{min}$ using the mixtures $\mathrm{MeOH}: \mathrm{H}_{2} \mathrm{O}(8: 2)(\mathrm{A})$ and isopropanol:MeOH (3:7) (B) in a gradient method (0-2 $\min 0 \% \mathrm{~B}, 14-23 \mathrm{~min} 100 \% \mathrm{~B}$, and $25-30 \mathrm{~min} 0 \% \mathrm{~B}$ ); detection was performed at $270 \mathrm{~nm}$. Electrospray ionization interface (ESI) was operated simultaneously in positive and negative ion modes (scan 100-2000 m/z), desolvation line temperature at $250{ }^{\circ} \mathrm{C}$, nitrogen as nebulizer gas at $1.5 \mathrm{~L} / \mathrm{min}$, drying gas at $8 \mathrm{~L} / \mathrm{min}$, and detector voltage at $1.4 \mathrm{kV}$.

\subsubsection{Gas Chromatography-Electron Impact Mass Spectrometry (GC/EIMS) Analysis}

Raw extracts were derivatized with $N$-methyl- $N$-trimethylsilyltrifluoroacetamide activated II ${ }^{\circledR}$ (Sigma, St. Louis, MO, USA). For each sample $(5 \mathrm{mg} / \mathrm{mL}), 200 \mu \mathrm{L}$ were dried into a chromatography vial with and insert; $20 \mu \mathrm{L}$ of the derivatization agent were then added and incubated at $60^{\circ} \mathrm{C}$ for one hour [31]. The analysis was carried out using a Trace 1300 LT gas chromatograph (Thermo Scientific, Waltham, MA, USA) equipped with an AI 1310 auto sampler, coupled to a Thermo ISQ Mass Spectrometer (using electron impact ionization and a single quadrupole analyzer), with a $60 \mathrm{~m} \times 0.25 \mathrm{~mm}$ ID $\times 0.25 \mu \mathrm{m}$ DB- 5 column $\left(\mathrm{Rxi}^{\circledR} 5\right.$ Sil MS, Restek, State College, PA, USA) using helium $(99.999 \%)$, with a flow of $1.5 \mathrm{~mL} / \mathrm{min}, 1 \mu \mathrm{L}$ of sample was injected in splitless mode, and the temperature of the injection port was $300^{\circ} \mathrm{C}$. The temperature program started with an initial temperature of $100{ }^{\circ} \mathrm{C}$ maintained for $1 \mathrm{~min}$, then increasing from $100^{\circ} \mathrm{C}$ to $250{ }^{\circ} \mathrm{C}$ at $15^{\circ} \mathrm{C} / \mathrm{min}$, and holding for $5 \mathrm{~min}$. It was then increased to $310^{\circ} \mathrm{C}$ at $10^{\circ} \mathrm{C} / \mathrm{min}$, and maintained for $30 \mathrm{~min}$. The ion source and transference line temperatures were $250^{\circ} \mathrm{C}$ and $310^{\circ} \mathrm{C}$, respectively. 


\subsection{Microscale Amended Medium (MSAM) Assay}

In vitro evaluation of mycelial growth inhibition against $F$. oxysporum was performed using an innovative, micro scale amended protocol using 12-well glass plates. A previously stirred mixture $(150 \mu \mathrm{L})$ containing Potato Dextrose Broth PDB $(25.0 \mathrm{~g} / \mathrm{L})$ and bacteriological agar $(0.5 \%)$ amended with extracts (distinctly adding the required amount of extract for succeeding the desired final concentration, such as $10.0,1.0$ and $0.1 \mu \mathrm{g} / \mu \mathrm{L}$, as treatment) was placed into each well as culture medium. The required amount of extracts to reach the final concentration was added to the warm medium, and the mixture was vigorously stirred using a vortex for 3 min until adequate dispersion was achieved, which resulted in the amended media. A 1-mm agar-mycelial plug from actively growing F. oxysporum cultures was inoculated onto the center of each well. Each test consisted of a randomized design with three replicates compared to a plate control (untreated medium; Figure 4). Prochloraz ${ }^{\circledR}$ was used as positive control. Each 12-well plate was placed into a humid chamber and allowed to incubate for $72 \mathrm{~h}$ at room temperature (average, $17^{\circ} \mathrm{C}$ ).

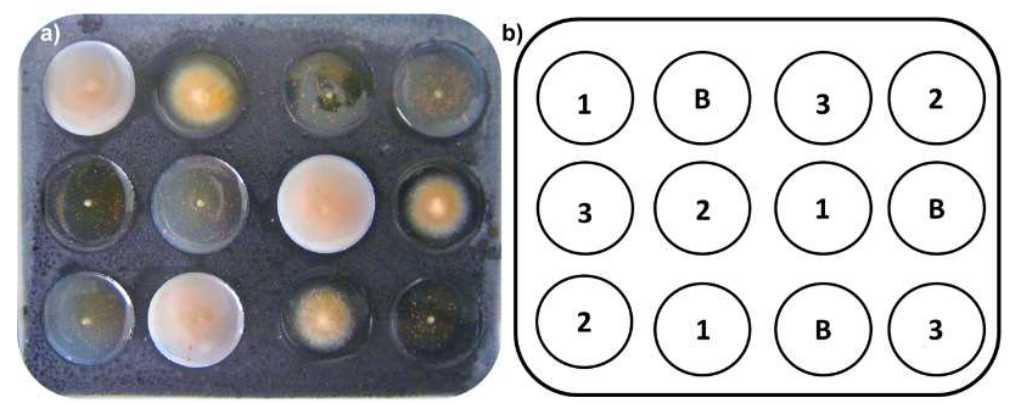

Figure 4. (a) Experimental unit (glass 12-well plates) for micro-scale amended medium (MSAM) assay. Each well was filled with medium $(150 \mu \mathrm{L})$ previously amended with extracts and then inoculated (F. oxysporum) using 1-mm plugs placed onto the center of each well. (b) A schematic representation of the randomly-organized experimental design for the MSAM assays; $\mathrm{B}=$ blank (F. oxysporum without treatment), each number $(1,2$, and 3$)$ indicates the treatment (in $\mu \mathrm{g} / \mu \mathrm{L}$ ) loaded into each well of the 12-well plate: $1=10 \mu \mathrm{g} / \mu \mathrm{L} ; 2=1.0 \mu \mathrm{g} / \mu \mathrm{L} ; 3=0.1 \mu \mathrm{g} / \mu \mathrm{L}$.

The plates were then photographed in a stereoscope (Optika ${ }^{\circledR}$ SZM-LED2, Ponteranica, Italy) and analyzed using ImageJ software (bundled with 64-bit Java 1.8.0_112, NIH, Bethesda, MD, USA, https://imagej.net). The inhibition percentage was calculated based on the area measured by ImageJ, compared to the control area, according to Equation (1):

$$
\% \text { inhibition }=100-\left(\frac{\text { Sample area }}{\text { Control area }} \times 100\right)
$$

\subsection{Statistical Analyses}

Total contents and antifungal activity data were subjected to the Shapiro-Wilks test, parametric analysis of variance (ANOVA), and Tukey's test $(p<0.05)$ using $\mathrm{R}$ project software version 3.0.2 (R Foundation, Vienna, Austria). In addition, the AR contents, ASCII-formatted LC-MS-derived data (previously aligned, normalized and autoscaled), and growth inhibition percentages against F. oxysporum were used to build the dataset. The resulting matrix was used for multivariate statistics (biochemometrics) through Single-Y orthogonal partial least squares (OPLS) regression using the SIMCA 13.0 software (Umetrics Inc., Umeå, Sweden).

\section{Conclusions}

AR-rich extracts from cereals showed inhibitory activity against F. oxysporum at different levels depending on the particular AR present. In this sense, negative ion mode LC-ESIMS profiles of acetone extracts revealed the presence of at least twelve main ARs. These findings were then supported by 
biochemometrics analysis combined with the development of a micro-scale amended medium (MSAM) protocol, which allowed us to evaluate small amounts of cereals-derived extracts. This combination (i.e., biochemometrics and MSAM) led to the identification of bioactive AR without the need for multiple bioactivity-guided isolation steps, thus improving the efficiency and productivity of antifungal discovery purposes. Therefore, multivariate statistical modeling (based on single-Y OPLS) revealed three ARs from a set of extracts that were responsible for the observed mycelial growth inhibition such as compounds 5, 8, and 10, which were also correlated by OPLS to the AR-rich mixtures. The results therefore indicate that these compounds, abundant in cereals, are important and valuable chemical entities that could eventually be included into advance experiments focused on F. oxysporum control. Further studies (e.g., biochemometrics-guided fractionation) are also required for isolating these compounds and to further validate our findings.

Author Contributions: Conceptualization, E.C-B.; methodology, R.M-C., L.O-D. and E.C-B.; software, L.O-D.; validation, R.M-C., L.O-D. and E.C-B.; formal analysis, R.M-C., L.O-D. and E.C-B.; resources, E.C-B.; data curation, R.M-C. and L.O-D.; writing-original draft preparation, R.M-C.; writing-review and editing, L.O-D. and E.C-B.; supervision, E.C-B.; project administration, E.C-B.; funding acquisition, E.C-B.

Funding: This research was funded by Vicerrectoría de Investigaciones at UMNG-Validity 2016, grant number IMP-CIAS-2293. Authors thank MU Nueva Granada by financial support.

Conflicts of Interest: The authors declare no conflict of interest.

\section{Appendix A}

Table A1. MS-based analyses of compounds 1-12 using three MS detectors coupled to chromatography: LC/LRESIMS LC/HRESIMS, GC/EIMS (after MSTFA derivatization).

\begin{tabular}{|c|c|c|c|}
\hline \multirow{2}{*}{ Comp. } & HRESIMS $^{a}$ & LRESIMS $^{b}$ & EIMS $^{\mathrm{c}}$ \\
\hline & $m / z(\%)$, Cluster & $m / z(\%)$, Cluster & $m / z(\%)$, Fragment \\
\hline 1 & $\begin{array}{c}389.3028(85)[\mathrm{M}-\mathrm{H}]^{-} \\
375.3259(100),[\mathrm{M}- \\
\left.\mathrm{CH}_{2}-\mathrm{H}\right]^{-} \\
343.3020(24),[\mathrm{M}- \\
\left.\mathrm{C}_{2} \mathrm{H}_{5} \mathrm{OH}\right]^{-}\end{array}$ & $389(100)$ & $\begin{array}{c}268(100)\left[(\mathrm{TMSO})_{2} \mathrm{C}_{6} \mathrm{H}_{4} \mathrm{CH}_{2}\right]^{+} \\
534(10)\left[\mathrm{M}+(\mathrm{TMS})_{2}\right]^{+}\end{array}$ \\
\hline 2 & $455.3891(15)[\mathrm{M}-\mathrm{H}]^{-}$ & $\begin{array}{c}\text { 455(70), }[\mathrm{M}-\mathrm{H}]^{-} \\
296(60) \\
574(50)\end{array}$ & $\begin{array}{c}268(100)\left[(\mathrm{TMSO})_{2} \mathrm{C}_{6} \mathrm{H}_{4} \mathrm{CH}_{2}\right]^{+} \\
600(10)\left[\mathrm{M}+(\mathrm{TMS})_{2}\right]^{+}\end{array}$ \\
\hline 3 & $\begin{array}{c}347.2976(100),[\mathrm{M}-\mathrm{H}]^{-} \\
695.5997(6),[2 \mathrm{M}-\mathrm{H}]^{-}\end{array}$ & $\begin{array}{l}347(100),[\mathrm{M}-\mathrm{H}]^{-} \\
695(60),[2 \mathrm{M}-\mathrm{H}]^{-}\end{array}$ & $\begin{array}{c}268(100)\left[(\mathrm{TMSO})_{2} \mathrm{C}_{6} \mathrm{H}_{4} \mathrm{CH}_{2}\right]^{+} \\
492(30)\left[\mathrm{M}+(\mathrm{TMS})_{2}\right]^{+}\end{array}$ \\
\hline 4 & $\begin{array}{c}373.3130(100),[\mathrm{M}-\mathrm{H}]^{-} \\
347.2971(30),[\mathrm{M}- \\
\left.\mathrm{C}_{2} \mathrm{H}_{2}-\mathrm{H}\right]^{-} \\
747.6278(5),[2 \mathrm{M}-\mathrm{H}]^{-}\end{array}$ & $\begin{array}{c}373(100),[\mathrm{M}-\mathrm{H}]^{-} \\
747(30),[2 \mathrm{M}-\mathrm{H}]^{-} \\
398(10)\end{array}$ & $\begin{array}{c}268(100)\left[(\mathrm{TMSO})_{2} \mathrm{C}_{6} \mathrm{H}_{4} \mathrm{CH}_{2}\right]^{+} \\
518(20)\left[\mathrm{M}+(\mathrm{TMS})_{2}\right]^{+}\end{array}$ \\
\hline 5 & $\begin{array}{l}375.3289(100),[\mathrm{M}-\mathrm{H}]^{-} \\
751.6652(13),[2 \mathrm{M}-\mathrm{H}]^{-}\end{array}$ & $\begin{array}{l}375(100),[\mathrm{M}-\mathrm{H}]^{-} \\
751(40),[2 \mathrm{M}-\mathrm{H}]^{-}\end{array}$ & $\begin{array}{c}268(100)\left[(\mathrm{TMSO})_{2} \mathrm{C}_{6} \mathrm{H}_{4} \mathrm{CH}_{2}\right]^{+} \\
520(40)\left[\mathrm{M}+(\mathrm{TMS})_{2}\right]^{+}\end{array}$ \\
\hline 6 & $\begin{array}{c}401.3413(40),[\mathrm{M}-\mathrm{H}]^{-} \\
375.3279(100),[\mathrm{M}- \\
\left.\mathrm{C}_{2} \mathrm{H}_{2}-\mathrm{H}\right]^{-} \\
803.6830(5),[2 \mathrm{M}-\mathrm{H}]^{-}\end{array}$ & $\begin{array}{l}401(100),[\mathrm{M}-\mathrm{H}]^{-} \\
803(15),[2 \mathrm{M}-\mathrm{H}]^{-}\end{array}$ & $\begin{array}{c}268(100)\left[(\mathrm{TMSO})_{2} \mathrm{C}_{6} \mathrm{H}_{4} \mathrm{CH}_{2}\right]^{+} \\
546(10)\left[\mathrm{M}+(\mathrm{TMS})_{2}\right]^{+}\end{array}$ \\
\hline 7 & $446.3693(50)[\mathrm{M}-\mathrm{H}]^{-}$ & $\begin{array}{c}446(50),[\mathrm{M}-\mathrm{H}]^{-} \\
1190(60)\end{array}$ & $\begin{array}{c}268(80)\left[(\mathrm{TMSO})_{2} \mathrm{C}_{6} \mathrm{H}_{4} \mathrm{CH}_{2}\right]^{+} 591 \\
(30)\left[\mathrm{M}+(\mathrm{TMS})_{2}\right]^{+}\end{array}$ \\
\hline 8 & $\begin{array}{l}403.3596(100),[\mathrm{M}-\mathrm{H}]^{-} \\
807.7275(45),[2 \mathrm{M}-\mathrm{H}]^{-}\end{array}$ & $\begin{array}{l}403(100),[\mathrm{M}-\mathrm{H}]^{-} \\
807(45),[2 \mathrm{M}-\mathrm{H}]^{-}\end{array}$ & $\begin{array}{c}268(100)\left[(\mathrm{TMSO})_{2} \mathrm{C}_{6} \mathrm{H}_{4} \mathrm{CH}_{2}\right]^{+} \\
548(30)\left[\mathrm{M}+(\mathrm{TMS})_{2}\right]^{+}\end{array}$ \\
\hline
\end{tabular}


Table A1. Cont.

\begin{tabular}{|c|c|c|c|}
\hline Comp. & HRESIMS a & LRESIMS $^{b}$ & EIMS $^{c}$ \\
\hline & $m / z(\%)$, Cluster & $m / z(\%)$, Cluster & $m / z(\%)$, Fragment \\
\hline 9 & $415.3187(80)[\mathrm{M}-\mathrm{H}]^{-}$ & $\begin{array}{c}415(65),[\mathrm{M}-\mathrm{H}]^{-} \\
901(45)\end{array}$ & $\begin{array}{c}268(100)\left[(\mathrm{TMSO})_{2} \mathrm{C}_{6} \mathrm{H}_{4} \mathrm{CH}_{2}\right]^{+} \\
560(10)\left[\mathrm{M}+(\mathrm{TMS})_{2}\right]^{+}\end{array}$ \\
\hline 10 & $\begin{array}{l}431.3903(100),[\mathrm{M}-\mathrm{H}]^{-} \\
863.7925(46),[2 \mathrm{M}-\mathrm{H}]^{-}\end{array}$ & $\begin{array}{l}431(100),[\mathrm{M}-\mathrm{H}]^{-} \\
863(46),[2 \mathrm{M}-\mathrm{H}]^{-}\end{array}$ & $\begin{array}{c}268(100)\left[(\mathrm{TMSO})_{2} \mathrm{C}_{6} \mathrm{H}_{4} \mathrm{CH}_{2}\right]^{+} \\
576(20)\left[\mathrm{M}+(\mathrm{TMS})_{2}\right]^{+}\end{array}$ \\
\hline 11 & $\begin{array}{c}479.3919(100),[\mathrm{M}-\mathrm{H}]^{-} \\
343.3036(51),[\mathrm{M}- \\
\left.\mathrm{C}_{10} \mathrm{H}_{16}-\mathrm{H}\right]^{-}\end{array}$ & $\begin{array}{l}479(100),[\mathrm{M}-\mathrm{H}]^{-} \\
959(37),[2 \mathrm{M}-\mathrm{H}]^{-}\end{array}$ & $\begin{array}{c}268(100)\left[(\mathrm{TMSO})_{2} \mathrm{C}_{6} \mathrm{H}_{4} \mathrm{CH}_{2}\right]^{+} \\
624(15)\left[\mathrm{M}+(\mathrm{TMS})_{2}\right]^{+}\end{array}$ \\
\hline 12 & $\begin{array}{l}459.4226(100),[\mathrm{M}-\mathrm{H}]^{-} \\
919.8549(40),[2 \mathrm{M}-\mathrm{H}]^{-}\end{array}$ & $\begin{array}{l}459(100),[\mathrm{M}-\mathrm{H}]^{-} \\
919(40),[2 \mathrm{M}-\mathrm{H}]^{-}\end{array}$ & $\begin{array}{c}268(100)\left[(\mathrm{TMSO})_{2} \mathrm{C}_{6} \mathrm{H}_{4} \mathrm{CH}_{2}\right]^{+} \\
604(20)\left[\mathrm{M}-(\mathrm{TMS})_{2}\right]^{+}\end{array}$ \\
\hline
\end{tabular}

${ }^{a}$ High-resolution mass spectrometry using a quadrupole-Time-of-Flight (QToF) tandem mass analyzer and electrospray ionization in negative ion mode coupled to an UFLC system; ${ }^{b}$ Low-resolution mass spectrometry using a single quadrupole mass analyzer and electrospray ionization in negative ion mode and coupled to an UFLC system; ${ }^{\mathrm{C}}$ Electron-impact mass spectrometry using a quadrupole mass analyzer coupled to a GC system after derivatization with MSTFA.

\section{References}

1. FAO Food and Agriculture Organization of the United Nations. Crop Prospects and Food Situation; Trade and Markets Division of FAO under the Global Information and Early Warning System (GIEWS): Rome, Italy, 2018; pp. 6-8.

2. Liangli, L.Y.; Tsao, R.; Shahidi, F. Cereals and Pulses: Nutraceutical Properties and Health Benefits; John Wiley \& Sons: Chichester, UK, 2012.

3. Kozubek, A.; Tyman, J.H.P. Resorcinolic lipids, the natural non-isoprenoid phenolic amphiphiles and their biological activity. Chem. Rev. 1999, 99, 1-26. [CrossRef] [PubMed]

4. Menzel, C.; Kamal-Eldin, A.; Marklund, M.; Andersson, A.; Åman, P.; Landberg, R. Alkylresorcinols in Swedish cereal food products. J. Food Compos. Anal. 2012, 28, 119-125. [CrossRef]

5. Arendt, E.K.; Zannini, E. 5-Triticale. In Cereal Grains for the Food and Beverage Industries; Woodhead Publishing: Cambridge, UK, 2013; pp. 201-219.

6. Landberg, R.; Kamal-Eldin, A.; Salmenkallio-Marttila, M.; Rouau, X.; Åman, P. Localization of alkylresorcinols in wheat, rye and barley kernels. J. Cereal. Sci. 2008, 48, 401-406. [CrossRef]

7. Athukorala, Y.; Hosseinian, F.S.; Mazza, G. Extraction and fractionation of alkylresorcinols from triticale bran by two-step supercritical carbon dioxide. LWT-Food Sci. Technol. 2010, 43, 660-665. [CrossRef]

8. Gasiorowski, K.; Szyba, K.; Brokos, B.; Kozubek, A. Antimutagenic activity of alkylresorcinols from cereal grains. Cancer Lett. 1996, 106, 109-115. [CrossRef]

9. Zarnowski, R.; Kozubek, A. Alkylresorcinol homologs in Pisum sativum L. varieties. Z. Naturforsch 1999, 54, 44-48. [CrossRef]

10. Stasiuk, M.; Kozubek, A. Biological activity of phenolic lipids. Cell Mol. Life Sci. 2010, 67, 841-860. [CrossRef] [PubMed]

11. Parikka, K.; Rowland, I.R.; Welch, R.W.; Wähälä, K. In vitro antioxidant activity and antigenotoxicity of 5- $n$-alkylresorcinols. J. Agric. Food Chem. 2006, 54, 1646-1650. [CrossRef]

12. Gani, A.; Wani, S.; Masoodi, F.; Hameed, G. Whole-grain cereal bioactive compounds and their health benefits: A review. J. Food Proc. Technol. 2012, 3, 146-156. [CrossRef]

13. Koistinen, V.M.; Hanhineva, K. Mass spectrometry-based analysis of whole-grain phytochemicals. Crit. Rev. Food Sci. Nutr. 2017, 57, 1688-1709. [CrossRef]

14. Biskup, I.; Zaczynska, E.; Krauze-Baranowska, M.; Fecka, I. Evaluation of cytotoxicity of 5- $n$-alkylresorcinol homologs and fraction on mouse fibroblast cell line L929. Eur. Food Res. Technol. 2017, 243, 1137-1148. [CrossRef]

15. Reiss, J. Influence of alkylresorcinols from rye and related compounds on the growth of food-borne molds. Cereal. Chem. 1989, 66, 491-493. 
16. Dey, E.S.; Ahmadi-Afzadi, M.; Nybom, H.; Tahir, I. Alkylresorcinols isolated from rye bran by supercritical fluid of carbon dioxide and suspended in a food-grade emulsion show activity against Penicillium expansum on apples. Arch. Phytopathol. Plant Protect. 2013, 46, 105-119. [CrossRef]

17. Tahir, I.; Ahmadi-Afzadi, M.; Nybom, H.; Dey, E. Rye bran alkylresorcinols inhibit growth of Penicillium expansum and Neofabraea perennans in vitro and in vivo on different apple cultivars. Eur. J. Hortic. Sci. 2014, 79, 218-225.

18. Ciccoritti, R.; Pasquini, M.; Sgrulletta, D.; Nocente, F. Effect of 5-n-alkylresorcinol extracts from durum wheat whole grain on the growth of Fusarium head blight (FHB) causal agents. J. Agric. Food Chem. 2015, 63, 43-50. [CrossRef] [PubMed]

19. Kienzle, S.; Carle, R.; Sruamsiri, P.; Tosta, C.; Neidhart, S. Occurrence of alk (en) ylresorcinols in the fruits of two mango (Mangifera indica L.) cultivars during on-tree maturation and postharvest storage. J. Agric. Food Chem. 2013, 62, 28-40. [CrossRef] [PubMed]

20. Karunanayake, K.; Sinniah, G.; Adikaram, N.; Abayasekara, C. Cultivar differences in antifungal activity and the resistance to postharvest anthracnose and stem-end rot in mango (Mangifera indica $L$ ). Australas. Plant Pathol. 2014, 43, 151-159. [CrossRef]

21. Dean, R.; Van Kan, J.A.; Pretorius, Z.A.; Hammond-Kosack, K.E.; Di Pietro, A.; Spanu, P.D.; Rudd, J.J.; Dickman, M.; Kahmann, R.; Ellis, J. The Top 10 fungal pathogens in molecular plant pathology. Mol. Plant. Pathol. 2012, 13, 414-430. [CrossRef] [PubMed]

22. Plazas-Jiménez, O.; Coy-Barrera, E. Antifungal activity of ultrasound-assisted acetone extract and alkylresorcinol-enriched fractions from Hordeum vulgare L. against Fusarium oxysporum. Cul. Trop. 2016, 37, 173-181.

23. Carrillo, L. Los Hongos De Los Alimentos Y Forrajes; Universidad Nacional de Salta: Salta, Argentina, 2003.

24. Summerell, B.A.; Salleh, B.; Leslie, J.F. A utilitarian approach to Fusarium identification. Plant Dis. 2003, 87, 117-128. [CrossRef]

25. Torres, G.A. Algunos aspectos de los hongos del género Fusarium y de la especie Fusarium oxysporum. Agron. Colomb. 2000, 17, 11-16.

26. Aoki, T.; O’Donnell, K.; Geiser, D.M. Systematics of key phytopathogenic Fusarium species: Current status and future challenges. J. Gen. Plant Pathol. 2014, 80, 189-201. [CrossRef]

27. Kellogg, J.J.; Todd, D.A.; Egan, J.M.; Raja, H.A.; Oberlies, N.H.; Kvalheim, O.M.; Cech, N.B. Biochemometrics for natural products research: Comparison of data analysis approaches and application to identification of bioactive compounds. J. Nat. Prod. 2016, 79, 376-386. [CrossRef] [PubMed]

28. Salek, R.M.; Steinbeck, C.; Viant, M.R.; Goodacre, R.; Dunn, W.B. The role of reporting standards for metabolite annotation and identification in metabolomic studies. GigaScience 2013, 2, 13. [CrossRef] [PubMed]

29. Sumner, L.W.; Amberg, A.; Barrett, D.; Beale, M.H.; Beger, R.; Daykin, C.A.; Fan, T.W.-M.; Fiehn, O.; Goodacre, R.; Griffin, J.L. Proposed minimum reporting standards for chemical analysis. Metabolomics 2007, 3, 211-221. [CrossRef] [PubMed]

30. Ross, A.B.; Åman, P.; Andersson, R.; Kamal-Eldin, A. Chromatographic analysis of alkylresorcinols and their metabolites. J. Chromatogr. A 2004, 1054, 157-164. [CrossRef]

31. Żarnowski, R.; Suzuki, Y.; Yamaguchi, I.; Pietr Stanisław, J. Alkylresorcinols in Barley (Hordeum vulgare L. distichon) Grains. Z. Naturforsch 2002, 57, 57-62. [CrossRef]

32. Basas-Jaumandreu, J.; López, J.; de las Heras, F.X.C. Resorcinol and $m$-guaiacol alkylated derivatives and asymmetrical secondary alcohols in the leaves from Tamarix canariensis. Phytochem. Lett. 2014, 10, 240-248. [CrossRef]

33. Nagy, K.; Ross, A.B.; Fay, L.B.; Bourgeois, A.; Kussmann, M. Gas chromatography/tandem mass spectrometry analysis of alkylresorcinols in red blood cells. Rapid Commun. Mass Spectrom. 2008, 22, 4098-4104. [CrossRef]

34. Zarnowski, R.; Suzuki, Y. Expedient Soxhlet extraction of resorcinolic lipids from wheat grains. J. Food Compos. Anal. 2004, 17, 649-663. [CrossRef]

35. Rebolleda, S.; Beltrán, S.; Sanz, M.T.; González-Sanjosé, M.L.; Solaesa, Á.G. Extraction of alkylresorcinols from wheat bran with supercritical $\mathrm{CO}_{2}$. J. Food Eng. 2013, 119, 814-821. [CrossRef]

36. Ross, A.B.; Shepherd, M.J.; Schüpphaus, M.; Sinclair, V.; Alfaro, B.; Kamal-Eldin, A.; Åman, P. Alkylresorcinols in cereals and cereal products. J. Food Eng. 2003, 51, 4111-4118. [CrossRef] [PubMed] 
37. Pihlava, J.-M.; Hellström, J.; Kurtelius, T.; Mattila, P. Flavonoids, anthocyanins, phenolamides, benzoxazinoids, lignans and alkylresorcinols in rye (Secale cereale) and some rye products. J. Cereal Sci. 2018, 79, 183-192. [CrossRef]

38. Gohil, S.; Pettersson, D.; Salomonsson, A.-C.; Åman, P. Analysis of alkyl- and alkenylresorcinols in triticale, wheat and rye. J. Sci. Food Agric. 1988, 45, 43-52. [CrossRef]

39. Hengtrakul, P.; Lorenz, K.; Mathias, M. Alkylresorcinol homologs in cereal grains. J. Food Compos. Anal. 1991, 4, 52-57. [CrossRef]

40. Al-Ruqaie, I.; Lorenz, K. Alkylresorcinols in extruded cereal brans. Cereal. Chem. 1992, 69, 472.

41. Barrero, A.F.; Sánchez, J.F.; Rodríguez, I. $N-\Delta^{13}$-Docosenoylanthranilic acid and alkylresorcinols from Ononis natrix subsp. hispanica. Phytochemistry 1990, 29, 1967-1969. [CrossRef]

42. Garcia, S.; Garcia, C.; Heinzen, H.; Moyna, P. Chemical basis of the resistance of barley seeds to pathogenic fungi. Phytochemistry 1997, 44, 415-418. [CrossRef]

43. Gembeh, S.V.; Brown, R.L.; Grimm, C.; Cleveland, T.E. Identification of chemical components of corn kernel pericarp wax associated with resistance to Aspergillus flavus infection and aflatoxin production. J. Agric. Food Chem. 2001, 49, 4635-4641. [CrossRef]

44. Rubert, J.; Righetti, L.; Stranska-Zachariasova, M.; Dzuman, Z.; Chrpova, J.; Dall'Asta, C.; Hajslova, J. Untargeted metabolomics based on ultra-high-performance liquid chromatography-high-resolution mass spectrometry merged with chemometrics: A new predictable tool for an early detection of mycotoxins. Food Chem. 2017, 224, 423-431. [CrossRef]

45. Mancini, V.; Romanazzi, G. Seed treatments to control seedborne fungal pathogens of vegetable crops. Pest Manag. Sci. 2014, 70, 860-868. [CrossRef] [PubMed]

46. Sampietro, D.A.; Vattuone, M.A.; Catalán, C.A.N. A new colorimetric method for determination of alkylresorcinols in ground and whole-cereal grains using the diazonium salt Fast Blue RR. Food Chem. 2009, 115, 1170-1174. [CrossRef]

Sample Availability: Samples are available from the authors.

(C) 2019 by the authors. Licensee MDPI, Basel, Switzerland. This article is an open access article distributed under the terms and conditions of the Creative Commons Attribution (CC BY) license (http://creativecommons.org/licenses/by/4.0/). 